\title{
Participation in Leisure and Sports by People with Disability Living in Rural Areas; Vision of Stakeholders in Quebec
}

\author{
${ }^{1}$ Emilie Belley-Ranger ${ }^{*}$, ${ }^{1}$ Romain Roult, ${ }^{1}$ Hélène Carbonneau, ${ }^{1}$ Isabelle Brunet \\ 1. Department of Leisure Studies, Culture and Tourism, Université du Québec à Trois-Rivières, Canada.
}

\begin{abstract}
People with disability face many constraints that affect their participation in leisure and sports, which can be seen in the gaps in the scientific literature. This study aims to document the specific issues in the leisure and sports participation of people with disability in rural areas. Qualitative research has documented the rurality-related items. Overall, stakeholders $(n=35)$ working with people with disability in rural areas were met in focus groups $(n=4)$. Strengths and difficulties have emerged from these testimonials. Being near the community facilitates awareness towards people with disability. However, one of the difficulties refers to the limited number of people with disability in the communities which obstructs the deployment of the leisure and sport offer. The second difficulty is the small number of volunteers and the problem of succession. Finally, availability and dilapidated infrastructure affects the participation in sports and recreation by people with disability in rural areas.
\end{abstract}

KEY WORDS: Leisure, Sport, Physical Activity, Rural Area, Disability.

\section{INTRODUCTION}

While obesity is a notorious problem with regard to public health, it affects rural populations even more (1). Several factors come into play including the increased number of constraints in physical activity and recreation in rural areas, additional financial difficulties compared to urban areas (2) and a greater dependence with relation to economic stability. Indeed, a company closure (3) or school (4) contributes to the devitalization of the area. The next section presents the obstacles in rural areas with regard to the practice of leisure and physical activity by people with disability: infrastructure, transportation, volunteering, insufficient leisure offer and location.
These financial difficulties in rural areas affect the availability of quality infrastructure which hinders the possibility of living an active lifestyle (5), a view shared by parents of children with disabilities (6). Rural infrastructure and equipment costs are too high for these areas (2). Rural areas must then turn to areas which are not dedicated to a PA infrastructure in order to promote the practice of sports and recreation.

As well, people from rural areas must travel considerable distances to have access to leisure and PA infrastructures (7). In addition to this constraint, time must be taken for travelling (2). Transportation issues are a major constraint for young adults who are in a school-to-work transition period (18 to 21 years old) (8) as well

*. Corresponding Author:

Emilie Belley-Ranger

E-mail: belley-ranger@uqtr.ca 
as for adults suffering from a traumatic brain injury (9). From this perspective, maintaining the infrastructure in the community becomes an attractive option in rural areas (9).

Financial difficulties previously mentioned also affect the hiring of dedicated, leisure staff (8). This leads to having to turn to volunteers, which, unfortunately, are few and far between (4, 10). On a more individual perspective, professional opportunities in rural areas for all people with or without disability are few (11).

The offer in leisure and PA in rural areas is weak and results from the high costs of programming (2). This insufficient supply in rural areas affects the acquisition of a healthy and active lifestyle (5). In this respect, we note that the establishment of a school program in rural areas can improve the participation of adolescents with an average intellectual disability (12). Moreover, it is found that rural recreation programs for people with disabilities are present in segregated form (13). Few recreational opportunities are offered by inclusion. This lack in terms of inclusion is the result of several factors including: (a) lack of awareness, (b) lack of knowledge on the inclusion, (c) lack of partnerships within communities, (d) accessibility constraints and a lack of transportation. To overcome this situation, the authors suggest increasing the training with recreation workers, and fostering partnerships between organizations and families.

However, these constraints are mitigated by one's strength and proximity to rural areas. Indeed, rural schools have a stronger sense of mutual aid between students with disabilities and students without disabilities (14). Indeed, contact between students with disabilities and their peers, even if they are infrequent, are pleasant, positive and respectful and possibly the result of an earlier own familiarity with the community. Nevertheless, it is interesting to stimulate contact between students in order to promote inclusion.

This study aims to document the specific issues in the leisure and sports participation of people with disabilities in rural Quebec. This study was conducted by the Laboratoire en loisir et vie communautaire at the University of Québec in Trois-Rivières (Canada) in collaboration with the project Choisir de Gagner: le défi des saines habitudes de vie pour les jeunes avec une limitation fonctionnelle [Choose to win: Adopting healthy lifestyle habits for youth with disabilities], an initiative of Alter Go Défi Sportif made possible with funding from Québec en Forme.

\section{MATERIALS AND METHODS}

A qualitative study allows the documentation of elements related to rurality. Four discussion groups of between 6 and 13 participants took place. These discussion groups, lasting approximately one and a half hours, took place in three different rural areas during 2016. Participants were recruited following a one-day training and awareness session regarding participation in leisure and PA activities for people with disability. The following themes were discussed:

- Current issues in your community / region with relation to the issue of physical activity and healthy lifestyles;

- Obstacles, needs and expectations with respect to the issue of physical activity and healthy lifestyles.

Focus groups represent an appropriate data collection method since it allows the grouping together of people interested in the same thing by creating interactions. In addition, focus groups provide an in depth understanding of social phenomena (15). The focus groups were conducted by a researcher and a research assistant. Recording of the sessions allowed an exact analysis of the focus groups' discussions. A thematic analysis helped determine topics related to the reality of their environment consisting of obstacles and challenges, needs to promote physical activity for young FHA (family housing allowance) people and the strengths and weaknesses of rural areas.

\section{RESULTS}

Sample descriptions. Participants $(n=35)$ have professional experience in this area $(M=$ 7.97 years, $S D=7.78$ ). They come from various professional backgrounds: schools, associations, municipal and health. Functional limitations of the younger participants are varied: autism spectrum disorder, physical disability, intellectual disability (ID), language disorder, hearing disability, visual disability, and other 
limitations (Trisomy 21 syndrome, ADHD, hemiplegia).

Qualitative results. The discussion groups took place in three different rural areas. Participants expressed the different rural elements affecting physical activity of people with disabilities in their community. In this respect, the strengths and weaknesses of rural areas have emerged. The next section describes these strengths and weaknesses.

The strength of rural areas with regard to the practice of leisure for youths with a disability is based on the proximity within the community. This proximity facilitates public awareness of the needs of youth with disabilities and, from an early age. The fact of having played and been in contact with one another before the first day of school facilitates the acceptance by peers at school. In this regard, one participant stated: "while we are not many, the little one who begins school and who has a lot of limitations, the teacher did not have to make the others as aware since the person was already familiar to them " (participant 25). This acceptance also takes place outside school, for example, during swimming lessons, "even when a child has a fit, no one points at him or, or is shocked by his behavior ..." (participant 32). People come together in the community and at events. Therefore, the community is seen as "one big family" (participant 25).

In terms of difficulties, there is not much in the way of leisure being offered. This is due, in particular, to the difficulty of having a sufficient pool of participants. This result affects the supply of adapted physical activities such as noted by this participant: "One of the challenges we have here is the critical mass, we say we have two young children under the age of 18 who are in wheelchairs, we could not make a basketball team (...)" (participant 1). Therefore, the leisure offer is suitable in urban areas, having the effect of adding constraints for transportation, required cost and time.

"If I sign my child up, I will sign him up in my community, in my area, while the adapted activity is not given everywhere, therefore, I have to go to the other end of town to be able to take part in the activity and pay the non-resident fee. I get there, and the time is inconvenient, for my kids, it takes them twice the amount of time to do their homework, and since school is a priority, it leaves little time for anything else." (participant 23).

The second problem regards infrastructures. On the one hand, their availability is fragile and secondly, their dilapidation makes them nonaccessible. Small areas are also dependent on the limited availability of leisure facilities. Should a facility close for various reasons, all leisure activities are affected. This is the case with larger facilities such as the municipal swimming pool or arena. Moreover, many of the infrastructures require renovations or modifications to meet the needs of people with disability. Thus, "an adaptation of the infrastructure needs to be considered, predicted and budgeted" (participant 27). According to the testimony of participants, accessibility to recreational facilities definitely needs to be improved.

The third difficulty related to rurality is the lack of volunteers. Volunteers are few and overloaded which encourages them to take on multiple activities relating to public recreation in the community. Therefore, as mentioned by this participant: "the volunteers are, as you say, often the same people everywhere and they run out of steam trying to organize all the activities" (participant 15). Rural areas have difficulty recruiting personnel in leisure and PA and must look towards more volunteer involvement. Consequently, the lack of resources and volunteers constrain the participation in leisure and sports of people with disability in rural areas.

\section{DISCUSSION}

The present study aims to document the specific issues for participation in recreation and PA by people with disability from rural areas. Strengths and weaknesses emerged from the four focus groups. The results highlight an undeniable force in rural areas, the proximity between the community members. This proximity greatly facilitates public awareness towards people with disability and their integration in schools as well as in extracurricular activities. This substantiates the literature which shows that in a school setting, 
contact between children with or without disabilities is positive and respectful (14). However, as noted by these authors, contacts are still infrequent. It should be emphasized that public awareness with regard to people with disability and their inclusion must be stimulated. However, this study has been able to illuminate the strength of proximity in rural areas in schools as well as in leisure PA in the community. The inclusion in leisure and PA is, therefore, preferred in rural areas while promoting the training of workers in leisure and PA and stimulating partnerships (13).

The analysis of our data shows that the lack of leisure activities in rural areas harms recreational and PA activities for the disabled (5). The major reason expressed by our participants is the difficulty of achieving a sufficient number of participants to be able to offer an activity. Our results show that children in rural areas do not always have access to a leisure activity in their community. Therefore, some parents must register their children in neighboring municipalities and provide transportation for them. Consequently, there are significant costs related to transportation and the payment of a non-resident tax. This finding corresponds to the reviewed literature (7). It is for this reason that recreation offered in the community may reduce the stress involved with transportation (9).

The unavailability and dilapidated infrastructures greatly affect the physical accessibility to places of practice. Indeed, participants mentioned the urgent need for accessibility to infrastructures. This agrees with the authors' conclusions stressing the fact that rural community infrastructures are too expensive for the financial capacities of rural areas (2). This is particularly important since, as pointed out, the lack of available infrastructures goes against a healthy and active lifestyle $(5,6)$.

According to our participants, the lack of volunteers is a major problem in the supply of leisure. Many organizations depend solely on volunteer involvement (10). This dependency creates pressure among volunteers, which results in exhaustion. Other authors point out that the economic fragility of rural areas causes devastating effects on community life of a municipality and volunteer involvement $(3,4)$. Our results show, however, that the lack of volunteers forces the sustainability of structures and leisure PA already in place. Due to financial difficulties, the hiring of leisure professionals is not possible; therefore, the task is left to volunteers.

\section{CONCLUSION}

This study has its strengths and limits. A major strength is the four discussion groups in rural areas that were used in order to better understand the people with disability's experience in their region. In a context where this study is in its infant stage, a qualitative research design was adopted, thereby giving the people in that area a voice. The setback to qualitative research is based on the inability to generalize the results. It reflects the reality of three rural areas only. Future research should explore other rural areas in order to better understand the problem. It should be studied further in order to identify exportable, inspiring practices to other rural areas.

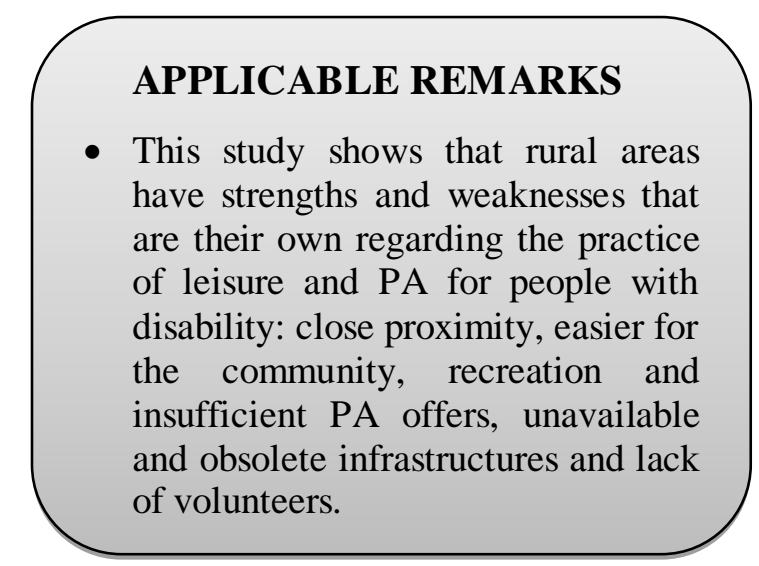

\section{REFERENCES}

1. Chief Medical Officer of Health Report. 2004 Chief Medical Officer of Health Report: Healthy Weights, Healthy Lives. Ontario, Canada: Medical Office of Health, Ministery of Health and Long-Term Care, 2004

2. Kowalski CL, Grybovych O, Lankford S, Neal L. Examining constraints to leisure and recreation for residents in remote and isolated communities: an analysis of 14 communities in the Northwest Territories of Canada. World Leisure Journal. 2012;54(4):322-36. 
3. Oncescu J. Rural restructuring and its impact on community recreation opportunities. Annals of Leisure Research. 2015;18(1):83-104.

4. Oncescu J, Giles A. A rural school's closure: Impacts on volunteers' gender roles. Rural Society. 2013;23(1):219.

5. Goodridge D, Rogers M, Klassen L, Jeffery B, Knox K, Rohatinsky N, et al. Access to health and support services: perspectives of people living with a long-term traumatic spinal cord injury in rural and urban areas. Disability and Rehabilitation. 2015;37(16):1401-10.

6. Law M, Petrenchik T, King G, Hurley P. Perceived environmental barriers to recreational, community, and school participation for children and youth with physical disabilities. Archives of physical medicine and rehabilitation. 2007;88(12):1636-42.

7. Roult R, Auger D, Adjizian J-M, Royer C. Exploring rural youth leisure behaviour in Québec: social findings and territorial issues. Leisure/Loisir. 2014;38(3-4):251-69.

8. Collet-Klingenberg LL, Kolb SM. Secondary and transition programming for 18-21 year old students in rural Wisconsin. Rural Special Education Quarterly. 2011;30(2):19-27.

9. Mitchell EJ, Veitch C, Passey M. Efficacy of leisure intervention groups in rehabilitation of people with an acquired brain injury. Disabil Rehabil. 2014;36(17):1474-82.

10. Federal/Provincial/Territorial Ministers Responsible for Seniors. Age-Friendly Rural and Remote Communities: A Guide Canada: Public Health Agency of Canada,,; 2006 [2016 30 June]. Available from: http://www.phacaspc.gc.ca/seniors-aines/alt-formats/pdf/publications/public/healthy-sante/age_friendly_rural/AFRRC_en.pdf.

11. Kingston G, Tanner B, Gray MA. The functional impact of a traumatic hand injury on people who live in rural and remote locations. Disabil Rehabil. 2010;32(4):326-35.

12. Sheppard L, Unsworth C. Developing Skills in Everyday Activities and Self-Determination in Adolescents With Intellectual and Developmental Disabilities. Remedial and Special Education. 2011;32(5):393-405.

13. Anderson L, Heyne L. A Statewide Needs Assessment Using Focus Groups: Perceived Challenges and Goals in Providing Inclusive Recreation Services in Rural Communities. Journal of Park and Recreation Administration. 2000;18(4):online.

14. Butler RS, Hodge SR. Social Inclusion of Students with Disabilities in Middle School Physical Education Classes. Research in Middle Level Education. 2004;27(1):1-10.

15. Creswell JW. Research Design: Qualitative, Quantitative, and Mixed Methods Approaches. 2nd ed: SAGE Publications; 2003. 246 p. 